\title{
Barrio Matadero-Franklin, de mercado popular a barrio artístico-cultural. Conservación y capitalización, a través de turismo creativo y co-creación
}

\author{
Stefania Pareti ${ }^{1}$ | Blanca García-Henche ${ }^{2}$ \\ Recibido: 09-07-2020 | en su versión final: 19-11-2020
}

Resumen

\begin{abstract}
El objetivo principal del presente trabajo es explorar cómo se puede conservar el patrimonio de un barrio artístico y cultural a través de la regeneración urbana y el desarrollo de polos creativos urbanos con contenido artístico-cultural. Se busca comprender los efectos en dichos barrios de las estrategias de marketing cultural. Se selecciona el Barrio Matadero-Franklin, en Santiago de Chile, un barrio icónico de mercados populares, escogido para desarrollar la XXI Bienal de Arquitectura y Urbanismo 2019. Se compara, además, su situación con otros casos relevantes de barrios y edificios convertidos en polos creativos. Metodológicamente se revisa la literatura sobre turismo creativo y de co-creación, se realizan entrevistas a actores clave del barrio y la Bienal y se analiza impacto del evento en los medios de comunicación. Se concluye que el Marketing Urbano y Cultural consigue posicionar la marca "Barrio Matadero-Franklin", obteniendo efectos socioeconómicos positivos en los diversos grupos de interés.
\end{abstract}

Palabras clave: ciudad; marketing cultural; redes de cooperación; Bienal de Arquitectura y Urbanismo

Citación

Pareti, S. y García Henche, B. (2021). Barrio Matadero-Franklin, de mercado popular a barrio artístico-cultural. Conservación y capitalización, a través de turismo creativo y co-creación. ACE: Architecture, City and Environment, 15(45), 9528. DOl: http://dx.doi.org/10.5821/ace.15.45.9528

\section{Matadero-Franklin, from Popular Market to Artistic-Cultural District. Conservation and Capitalization, Through Creative Tourism and Co-creation}

Abstract The main objective of this work is to explore how to preserve the heritage of an artistic and cultural district, through urban regeneration and the development of urban creative centers with artistic and cultural content. The aim is to understand the effects of cultural marketing strategies in different districts. Matadero-Franklin is selected in Santiago of Chile, an iconic district of popular markets, chosen to develop the XXI Biennial of Architecture and Urbanism 2019. It also compares its situation with other relevant cases of districts and buildings converted to creative poles. Methodologically, literature on creative and co-creation tourism is reviewed, interviews are made with key actors from the district and from the Biennial, plus the analysis of the event impact on press media. It is concluded that the Urban and Cultural Marketing can empower "Matadero-Franklin district" as a brand, obtaining positive socio-economic effects in various interest groups.

Keywords: city; cultural marketing; cooperation networks; Architecture \& Urbanism Biennial

1 Dra. Economía y Gestión de Empresas. Profesora investigadora, Universidad Andrés Bello (ORCID: $\underline{0000-}$ 0003-0515-5389); ${ }^{2}$ Dra. Ciencias de la Dirección. Profesora contratada Doctor, Facultad de CCEE y Turismo, Universidad de Alcalá de Henares (ORCID: 0000-0002-9824-7372) Contacto: s.pareti@uandresbello.edu, blanca.garcia@uah.es

ACE, 15 (4.5) CC BY-ND 3.0 ES | UPC Barcelona, España | Barrio Matadero-Franklin, de mercado popular a barrio artístico-cultural. Conservación y capitalización, a través de turismo creativo y co-creación. DOI http://dx.doi.org/10.5821/ace.15.45.9528 


\section{Introducción}

Ante la creciente crítica de la comunidad académica frente al hecho que las Bienales sólo se realizan en el marco de grandes obras arquitectónicas que requieren a su vez grandes presupuestos e inversión, la XXI Bienal de Arquitectura y Urbanismo de Santiago de Chile abre espacio al concepto La Feria Libre "Lo Común y lo Corriente" (Monroy y Coeffé, 2019). Dicho evento tiene como objetivo integrar en una mirada el espacio tanto público como privado, poniendo especial atención a lo cotidiano, que viene a tener un rol característico y auténtico. El siglo XXI se ha caracterizado por el crecimiento del arte de lo cotidiano y lo mundano (Juarranz, 2017).

En la XXI Bienal de Arquitectura y Urbanismo se trata de significar y entregar valor a lo cotidiano. El proyecto incorpora a diversos grupos de interés, tales como la sociedad civil, comunidades locales del barrio, emprendedores, juntas comunales y de vecinos, estudiantes universitarios, comunidad académica y ayuntamiento de Santiago, entre otros. Por otro lado, el patrimonio y los bienes culturales, para que se hagan vivos, deben gestionarse bajo una marca que los identifique y reconozca como tal. Así ocurre con la marca Barrio Matadero-Franklin que, utilizando estrategias de marketing urbano y cultural, trata de logran un posicionamiento yendo más allá de "la moda" de un evento per sé.

\subsection{Problema de investigación y su importancia}

El presente trabajo tiene como objetivo principal investigar la manera en que el desarrollo de estrategias de turismo creativo y co-creación puede generar efectos positivos en el progreso socioeconómico de un barrio emplazado en un espacio geográfico delimitado. Se selecciona a Barrio Matadero Franklin, debido a que (1) es un espacio urbano delimitado, (2) cuenta con oferta cultural, comercial y de servicios diferenciados y únicos, (3) es reconocido como el barrio de mercados populares, (4) es un barrio en fase de crecimiento en cuanto a desarrollo hacia barrio con valor artístico-cultural y (5) fue seleccionado como Barrio estratégico para realizarse la Bienal bajo el manifiesto "lo común y lo corriente".

\subsection{El Barrio Matadero-Franklin}

La historia del barrio data al 1847 cuando surge Población Matadero, la primera población urbana del sector, en los alrededores del zanjón de la Aguada y la calle San Diego. Dichas calles eran rutas estratégicas que comunicaban a la capital chilena con las provincias y servían para la comercialización de productos con el sur del país. Desde 1868 el matadero pasa a manos del gobierno local, que otorga la concesión de este al empresario Diego Tagle. En esos años, Matadero-Franklin se consolida como el principal polo comercial del sector sur de Santiago de Chile, siendo el más importante polo de faenamiento, compra y venta de animales.

En 1890, se establece el Tren de Circunvalación de Santiago y se edificó la Estación San Diego a sólo una cuadra del matadero, lo que favoreció el incremento de transacciones comerciales, gracias a la conexión estratégica directa con la Estación Central. La Estación Matadero, funcionó sólo hasta la década del setenta del siglo pasado, cuando este ferrocarril fue desmantelado y dejó de operar.

Llegado el inicio del siglo XX, la población en Santiago aumentó, generándose un incremento en la demanda de carne, lo que obligó a la modernización del matadero para poder cubrir dicha demanda.

En 1911 se inaugura la Población Huemul, primer conjunto de vivienda social gestionado por el Estado y en 1912 se inaugura la Población Matadero, compuesta por viviendas modernas. La tipología de

ACE, 15 (4.5) CC BY-ND 3.0 ES | UPC Barcelona, España | Barrio Matadero-Franklin, de mercado popular a barrio

artístico-cultural. Conservación y capitalización, a través de turismo creativo y co-creación. DOI http://dx.doi.org/10.5821/ace.15.45.9528 
habitantes de dicho barrio venía principalmente marcada por trabajadores en oficios relacionados al matadero y clase obrera, la cual posteriormente se involucró fuertemente en el comercio de los mercados que allí se han ido desarrollando hasta la fecha. En los orígenes del barrio, los arquitectos Hermógenes del Canto y Alberto Schade, construyeron nuevos pabellones para producir por separado y en serie de cada tipo de animal faenado.

En 1930 debido a la gran depresión de 1929, en el barrio comienza a proliferar un masivo mercado persa. A partir de ese momento, se comienza a generar una intensa actividad comercial el sector, delimitado por las calles Franklin, Placer, San Francisco y Magallanes, siendo históricamente un barrio obrero con venta de productos con escasa diferenciación y valor agregado.

En 1975 suspende el funcionamiento el Matadero de Franklin y para el 1980 comienzan a aparecer extensos galpones de comercio que fueron cedidos por el ayuntamiento a los vendedores ambulantes. En la actualidad, se mantienen los edificios icónicos del barrio, tales como el Teatro Huemul, el Matadero Franklin-Galpón Matadero, la plaza de los Toros y el Persa Víctor Manuel-Galería La Curtiembre. Hoy en día, se están desarrollando nuevos polos culturales hipster que atraen a artistas jóvenes a explorar el barrio. Tal es el caso del Persa Víctor Manuel, emplazado entre las calles Bío-Bío, Víctor Manuel, Placer y San Isidro. El edificio dónde se ubica, se construyó a inicios de siglos aproximadamente para albergar una Curtiembre y Fábrica de Cueros y Calzados de Ayçaguer y Duhalde. Cuenta con aproximadamente 24.000 m2, sus espacios se distribuyen en dos niveles: 17.500 $\mathrm{m} 2$ en la primera planta y $6.500 \mathrm{~m} 2$ en la segunda planta. Posee seis galpones y ocho sectores de gran riqueza arquitectónica, inspirada y heredada de su tradición abocada a la arquitectura industrial (Figura 1).

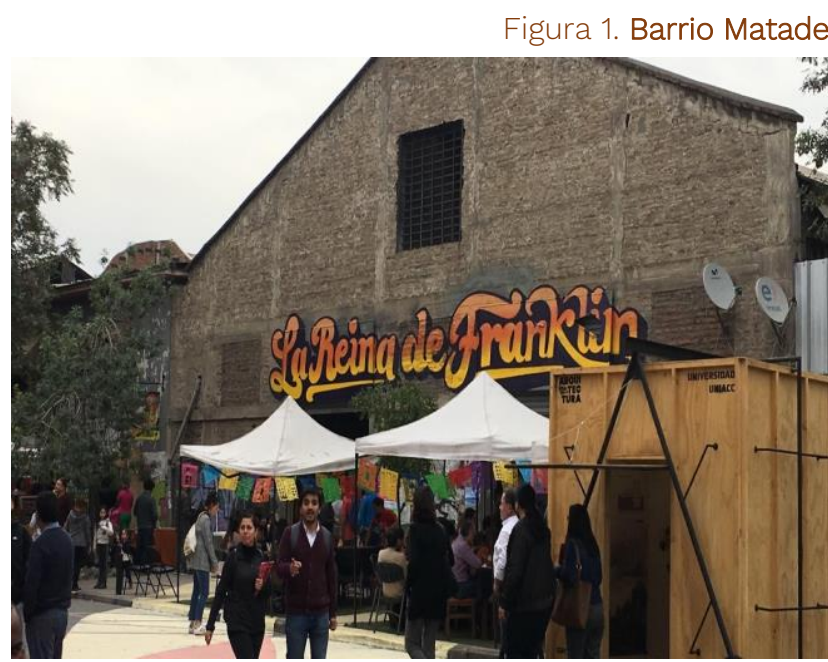

Nota: ejemplo de fachado de uno de los galpones tradicionales del barrio en la actualidad.

Fuente: Fotografía de autoras.

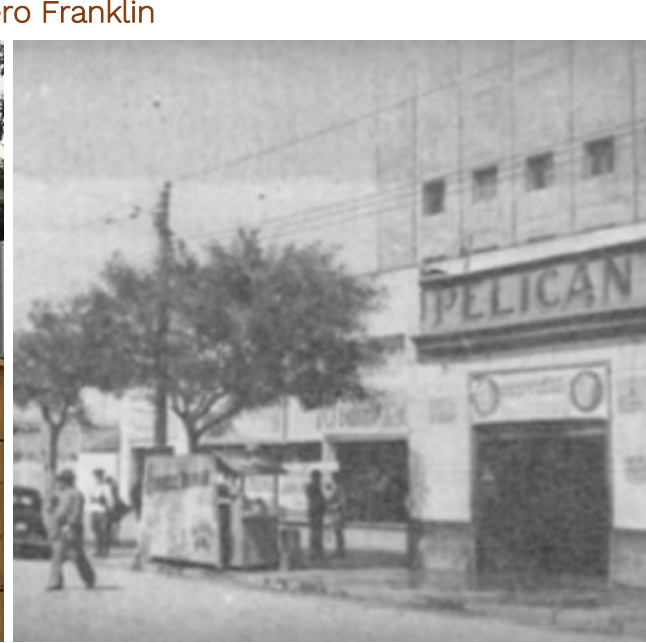

Nota: ejemplo de fachado con Cine Prat, ícono de tradición y encuentro en del barrio en 1939. Fuente: Moreno, M.B, (2019)

En la actualidad, existen cerca de mil locales que presentan una oferta variada y artículos únicos en su mayoría vintage y con gran valor debida a su escasez. Los locales se encuentran segmentados por diversos rubros, tales como libros, muebles, electrónica, antigüedades, videojuegos, entre otros.

Dentro del Persa Víctor Manuel se emplaza una galería de arte interior, denominada la Curtiembre, realizada por la artista Paula Godoy Ossa, emplazada sobre un mural de aproximadamente $600 \mathrm{~m}^{2}$ denominado "Local 54". En dicha galería, semanalmente, se realizan exhibiciones artísticas, emprendedores, venta objetos vintage son un tesoro para los coleccionistas, eventos de marcas y

ACE, 15 (4.5) CC BY-ND 3.0 ES | UPC Barcelona, España | Barrio Matadero-Franklin, de mercado popular a barrio

artístico-cultural. Conservación y capitalización, a través de turismo creativo y co-creación. DOI: http://dx.doi.org/10.5821/ace.15.45.9528 
actividades culturales para toda la familia o para quienes, simplemente, busquen experiencias de ocio diferenciadas. Existe, además, una oferta gastronómica con doce locales de comida regional.

Adyacente a la galería, se encuentra una plaza interior, justo en corazón del Persa Víctor Manuel, donde se realizan actividades recreativas, musicales, artísticas y culturales. El Arte Urbano ha proliferado en el barrio y, desde el 2016, el Persa invita a reconocidos artistas para realizar murales, tanto en el exterior e interior, consolidando un circuito de arte urbano. El objetivo de la iniciativa, según la Web oficial que es la Guía del Barrio Matadero Franklin, es lograr transformar y posicionar al Persa Víctor Manuel como referente de la cultura del Arte Urbano en Santiago y Latinoamérica.

Existen numerosos ejemplos a nivel mundial de actividades de recuperación de Arquitectura Industrial bajo un prisma creativo para uso de actividades culturales y de ocio, similares a Matadero Franklin.

Se podrían citar los siguientes:

- Matadero en Madrid dentro del Proyecto Madrid Río: Proyecto de revitalización de un antiguo barrio y matadero, dónde se ha generado un nuevo polo cultural y de áreas verdes para la ciudad.

- LX Factory en Lisboa: Recuperación y salvaguarda del patrimonio industrial de la Companhia de Fiação e Tecidos Lisbonense situada en el barrio de Alcantara, actualmente se ha desarrollado un nuevo uso del espacio con fines artísticos, comerciales y culturales.

- Meathpacking en Nueva York: Proyecto de recuperación patrimonial en la antigua zona de matadero, actualmente es un distrito de ocio, restauración y arte.

Existen, además, numerosos ejemplos de recuperación en edificios con patrimonio industrial que se utilizan en la actualidad con fines artístico-culturales como:

- Tate Modern en Londres, museo emplazado en la antigua central de energía de Bankside.

- Caixa Forum en Madrid, centro de exposiciones artísticas y culturales emplazado en la antigua central de energía de Madrid.

- Fundación Canal Isabel II en Madrid, centro de exposiciones artísticas y culturales emplazado en una antigua estación elevadora.

- Centro Azuna, en Bilbao, es un antiguo almacén de vino ubicado en el centro del Bilbao reconvertido en centro de ocio y cultura, con sala de exposiciones, cine, biblioteca, tienda, restaurantes y otros servicios.

- Edificios de las antiguas fábricas de la empresa Tabacalera Española en Madrid y Tabakalera, en San Sebastián, convertidos en centros culturales y de ocio experimental.

Los casos anteriormente citados, que son casos de éxito en la recuperación de edificios industriales con un prisma creativo y que se han convertido en centros de ocio cultural para los habitantes y visitantes de las diferentes ciudades, suponen una muestra del camino que debería seguir MataderoFranklin como estrategia de posicionamiento y desarrollo, tras finalizar la XXI Bienal.

\section{XXI Bienal de Arquitectura y Urbanismo, La Feria Libre y "Lo Común y lo Corriente"}

La Bienal de Arquitectura y Urbanismo de Chile fue creada por el directorio del Colegio de Arquitectos en 1977. Se repite cada dos años convirtiéndose en el espacio de encuentro más relevante para la discusión de la disciplina a nivel nacional. Este evento nacido en Chile es incluso tres años más

ACE, 15 (45) CC BY-ND 3.0 ES | UPC Barcelona, España | Barrio Matadero-Franklin, de mercado popular a barrio artístico-cultural. Conservación y capitalización, a través de turismo creativo y co-creación. DOI http://dx.doi.org/10.5821/ace.15.45.9528 
antiguo de la Bienal de Venecia, 1980, por lo cual es un encuentro de alto impacto en Latino América y en el qué hacer de la Arquitectura, Diseño y Geografía.

La edición del 3 al 27 de octubre del 2019 se materializa en las ciudades y barrios de: Iquique-Alto Hospicio, La Serena-Coquimbo, Puerto Montt-Puerto Varas y Santiago-Matadero Franklin. El criterio de elección de las localizaciones recayó en la presencia de universidades en cada uno de ellos, junto con delegaciones zonales del Colegio de Arquitectos. La XXI edición de la Bienal, se gesta con el fin de enfocar la arquitectura no sólo a magnas obras que requieren amplios presupuestos para su desarrollo. Se pone, así, el foco en "lo común y lo corriente" bajo una mirada de lograr percibir lo maravilloso en lo cotidiano. Dado lo anterior se involucraron diversos grupos de interés en su realización de dicha XXI Bienal:

- Educación: Escuela de Arquitectura, Facultad de Arquitectura, Diseño y Estudios Urbanos, Facultad de Arquitectura y Urbanismo de la Universidad de Chile, Universidad de Valparaíso Chile, Universidad Técnica Federico Santa María, Universidad Tecnológica Metropolitana, Universidad San Sebastián, etc.

- Medios Asociados: ArchDaily, Radio Bío-Bío, periódico La Cuarta y Radio Franklin.

- Apoyo General: Fundación Quiero mi Barrio (programa de recuperación de barrios), Instituto Nacional de la Juventud de Chile, Corporación para el desarrollo de Santiago, Grupo Asociativo local Franklin, Barrio Huemul Vecinos con Patrimonio, Junta de Vecinos y Vecinas Adelante al Progreso y Buen Día agencia de diseño gráfico.

\section{Turismo Creativo y Co-Creación}

La ciudad se considera como la forma y el símbolo de una relación social integrada, es considerada el lugar dónde se encuentra desde; la academia, un templo, hasta el mercado. Es producto de la tierra, del tiempo y nace de una necesidad social del individuo que la habita o transita (Mumford, 2016). El concepto de ciudades creativas data de 2002 con los estudios de Richard Florida, quién argumenta que, son las clases creativas dentro de las ciudades, las que actúan en pos del desarrollo económico de estas (Mc Guigan, 2016). La base de esta teoría se encuentra en las 3T del desarrollo económico: tecnología, talento y tolerancia (Florida, 2002). Esta teoría a su vez ha sido criticada debido a lo foco sólo en el ámbito económico, dejando al descubierto el desarrollo social (Peck, 2005 y Scott, 2006).

Posteriormente se ha desarrollado el concepto de sostenibilidad cultural, que incorpora la creatividad sustentable junto a "resiliencia" y "serendipia", yendo un paso más allá de objetivos sólo económicos que requiere el desarrollo de la ciudad (Kirchberg y Kagan, 2013).

La creatividad ha sido una pieza fundamental para el desarrollo turístico (Richards, 2014) y en la planificación de ciudades y políticas de marketing urbano (Vanolo, 2008). Se ha utilizado para transformar el turismo cultural, migrando desde una mirada que sólo ponía atención a la herencia tangible de los destinos, hacia una que también involucre aspectos intangibles y que resulten relevantes a la experiencia (Richards, 2011). La cultura comenzó a vincularse al turismo desde el 1970 cuándo se abrió espacio a eventos culturales, festivales, teatros y cines, etc., para consolidar la imagen de los destinos (Richards y Wilson, 2007).

La cultura y la creatividad han sido pilares clave en las agendas de política urbana para el desarrollo del territorio, más aún cuando se equilibran con políticas sociales para desarrollar socioeconómicamente el territorio, como ha ocurrido en el caso de Copenague, en Dinamarca (Bayliss, 2007).

ACE, 15 (4.5) CC BY-ND 3.0 ES | UPC Barcelona, España | Barrio Matadero-Franklin, de mercado popular a barrio 5 artístico-cultural. Conservación y capitalización, a través de turismo creativo y co-creación. DOI http://dx.doi.org/10.5821/ace.15.45.9528 
La cultura sí es una herramienta para el desarrollo local de las ciudades, los recursos culturales fomentan además constante renovación física, económica y social, tal como se observó en el caso de la proyección de Matera 2019 como proyecto de capital cultural, dónde se observó trabajo colaborativo para consolidar el territorio (Felicetti, 2016). La gestión de la cultura puede llegar a ser una estrategia de transformación y promoción urbana, tal fue el caso de Medellín y Bogotá (Duque Franco, 2015).

La ciudad cultural no sólo debe ser para los turistas, debe integrar a su comunidad local, para ello se han desarrollado política de co-creación, tal como "Playtown" en Recife, dónde se integró la tecnología como factor crítico para co-crear experiencias tanto materiales como sociales que afecten positivamente a la ciudad (Marques y Borba, 2017).

Para mantener y desarrollar destinos culturales, se deben considerar los siguientes elementos: 1) se deben respetar e integrar la diversidad cultural de los residentes 2) las ciudades deben diseñar y destinar recursos para el desarrollar cultural de estos 3) debe haber transparencia en los permisos que permitan el desarrollo de actividades culturales junto a la comunidad local 4) las agencias culturales deben integrarse y actualizarse en políticas que impacten positivamente la actividad cultural 5) en caso de ser necesario debiese existir una autoridad cultural (Rosensteing, 2011).

Para que el turismo cultural y la regeneración urbana sea a largo plazo, debe integrar y considerar a la comunidad local y no sólo a los turistas, junto con una consolidación de la imagen de destino, junto con respetar el desarrollo social, económico y medioambiental (Sepe y Di Trapani, 2010, Napadensky, 2020, De Jorge-Huertas, 2020).

Analizados diferentes casos de distintas ciudades se puede concluir que la cultura y patrimonio cultural de los destinos resultan ser facilitadores del desarrollo de estos y, el turismo actúa en pro de ello (Richards, 2000), haciendo que las ciudades sean espacios que generan experiencias. La cultura es, así, un facilitador para alcanzar desarrollo económico y cohesión social (Hudson, Sandberg y Schmauch, 2017). Los eventos culturales y el desarrollo de turismo cultural han estado altamente presente en las capitales europeas de la cultura, lo cual ha facilitado mejoras en la economía local, incremento del reconocimiento de imagen de marca de destino, regeneración urbana y promover el consumo cultural junto con la generación de redes (Liu, 2014).

Por otra parte, el Fórum de Ciudades y Territorios Creativos de España (2017), considera que las ciudades se están convirtiendo en 'paisajes creativos', dejando de ser lugares donde vivir, para transformarse en un paisaje en el que disfrutar, experimentar y degustar. Por ello, se hace necesario la construcción de nuevos modelos urbanos, como ciudades sostenibles donde lo local, la preservación del patrimonio y las experiencias innovadoras cobren cada vez más fuerza. Ante la tendencia a la globalización y gentrificación urbana, a todos los niveles, existen otras apuestas que reclaman la transformación de los espacios geográficos manteniendo las características originales de los mismos (predominio de la pequeña empresa, importancia de las relaciones locales, recuperación y mantenimiento del patrimonio urbano, etc.) y con consecuencias económicas positivas sobre dichas empresas locales (Amin y Robins, 1992).

Los distritos creativos han de ser planificados y coordinados para evitar fenómenos de gentrificación y desplazamientos potenciales de la población local, tal como ha ocurrido en los distritos creativos de Nueva York, desde Greenwich Village hasta Bushwick (Zukin y Braslow, 2011). La ciudad creativa puede ser trabajada para desarrollar una imagen deseada, tal es el caso del trabajo respecto a la marca urbana "Turín" como marca de ciudad creativa, yendo un paso más allá de su concepción habitual de ser una ciudad industrial, desarrollando nuevas acciones tales como Terra Madre, La noche de los Investigadores, la Noche Blanca (Adamo, Ferrari y Gilli, 2019). El turismo creativo es una

ACE, 15 (4.5) CC BY-ND 3.0 ES | UPC Barcelona, España | Barrio Matadero-Franklin, de mercado popular a barrio

artístico-cultural. Conservación y capitalización, a través de turismo creativo y co-creación. DOI http://dx.doi.org/10.5821/ace.15.45.9528 
oportunidad para lugares pequeños, ya que los barrios de pequeñas dimensiones no tienen por qué intentar ser como los de gran escala para ganar posicionamiento e imagen de marca, sino que han de desarrollar sus capacidades endógenas para desarrollarse (Richards, 2019). Las políticas de cultura creativa incrementan la atracción de las ciudades, promoviendo además el turismo cultural de ellas. En Portugal, se analizó cómo es que las actividades de turismo creativo pueden crear valor social a las comunidades locales, incrementando el sentido de pertenencia de sus habitantes (Bakas, Duxbury, Remoaldo y Matos, 2019). Siguiendo la idea anterior se estudió el rol de la Bienal de Arte en Helsinki como estrategia de placemaking y city branding, se concluye que los eventos culturales facilitan el desarrollo urbano, social y económico de los destinos (Radaelli-Muuronen,2019).

El turismo creativo como constructo ha sido analizado de diversas aristas, una de ellas es su transición al concepto de turismo de experiencias participativas, son el afán de generar mayor vínculo con los diversos grupos de interés involucrados (De Bruin y Jelinčić, 2016). El turismo creativo ha logrado revitalizar espacios públicos, a través de la participación activa y talleres creativos, que incorporen tanto a los turistas como a sus residentes (Rabazauskaité, 2015). La ciudad creativa incluso puede ser una marca en sí, tal como ocurrió en la ciudad de Łódź en Polonia, dónde el 2012 las autoridades locales adoptaron una estrategia de ciudad de las industrias creativas para fomentar su consolidación e imagen de ciudad (Brzozowska, 2016). A través de todos los casos anteriormente citados, se puede afirmar que el turismo creativo resulta ser el nuevo desafío en el desarrollo de destinos que ha de enfocarse hacia un turismo experiencial, dónde la cultura esté presente. La red de ciudades creativas, proclamadas por la UNESCO, tiene como principal fin valorar la creatividad y las industrias culturales, ampliado la creación, la producción, la difusión y distribución de actividades y bienes y servicios culturales e integrando la cultura en los planes de desarrollo local y regional e internacional.

\section{Metodología}

La presente investigación se organizó con un análisis y recopilación de datos de fuentes secundarias y primarias. La investigación primaria cualitativa se basa en entrevistas realizadas a vecinos y propietarios de locales comerciales en el barrio. Dichas entrevistas están recogidas en la guía "LO Común y lo corriente" editada por la XXI Bienal de Arquitectura y Urbanismo de Chile editada el 2019 (la guía recoge 600 entrevistas realizadas entre marzo y mayo de 2019). Respecto a los datos secundarios, se ha realizado una revisión del estado de la cuestión respecto a las investigaciones existentes respecto a co-creación y turismo creativo y se han analizado ejemplos de otros casos de recuperación y conservación del patrimonio con fines creativos, con artículos de investigaciones recientes al respecto. Por otra parte, se ha realizado un análisis, a través de la revisión de datos secundarios aparecidos en prensa tradicional y prensa online, notas de prensa, webs, guías turísticas, etc., de la creación de la identidad de barrio artístico-cultural a través del desarrollo de la Bienal de Arquitectura y Urbanismo y el impacto en los medios de comunicación.

\section{Resultados}

Los resultados de la investigación se muestran desde dos prismas. Por un lado, se analizan los resultados más relevantes obtenidos de las entrevistas a actores claves seleccionados, utilizando las nubes de palabras como instrumento para mostrar los conceptos más representativos para los agentes involucrados. Por otra parte, se presenta la creación de la identidad de barrio artístico-cultural a través del desarrollo de la Bienal de Arquitectura y Urbanismo con foco en la Común y lo Corriente,

ACE, 15 (4.5) CC BY-ND 3.0 ES | UPC Barcelona, España | Barrio Matadero-Franklin, de mercado popular a barrio

artístico-cultural. Conservación y capitalización, a través de turismo creativo y co-creación. DOI: http://dx.doi.org/10.5821/ace.15.45.9528 
posicionando la marca "Barrio Matadero Franklin" junto con su corazón cultural "Persa Víctor Manuel" como distrito cultural, más allá de mercado popular.

\subsection{Resultados relevantes obtenidos de las entrevistas a actores claves}

Se muestra la nube de palabras correspondiente al conjunto de preguntas conceptuales de la sesión de entrevista realizadas a actores que se consideran representativos para "la voz del barrio", recogidas en el catálogo de la Bienal (figuras 2 y 3).

Las preguntas realizadas en la entrevista fueron realizadas por el Equipo de Levantamiento Territorial y comunitario de la XXI Bienal de Arquitectura y Urbanismo de Chile y son las siguientes:

- ¿Para qué sirven los arquitectos y arquitectas?

- ¿Qué tan común es recibir servicios de arquitectura?

- ¿Cuántas personas conoces que hayan contratado a un arquitecto o arquitecta?

- ¿Qué es la arquitectura?

- ¿Qué te gustaría o esperas recibir de parte de un arquitecto o arquitecta algún día?

- ¿Qué esperas de la Bienal de Arquitectura en octubre?

En la (Figura 2) se recogen las ideas de los entrevistados sobre el concepto Arquitectura, mientras que, en la (Figura 3) se analizan los conceptos referentes al evento concreto que representa la Bienal para los entrevistados.

Figura 2. Nube de palabras correspondientes a la sesión de entrevistas a

"La voz del barrio Matadero Franklin" sobre Arquitectura

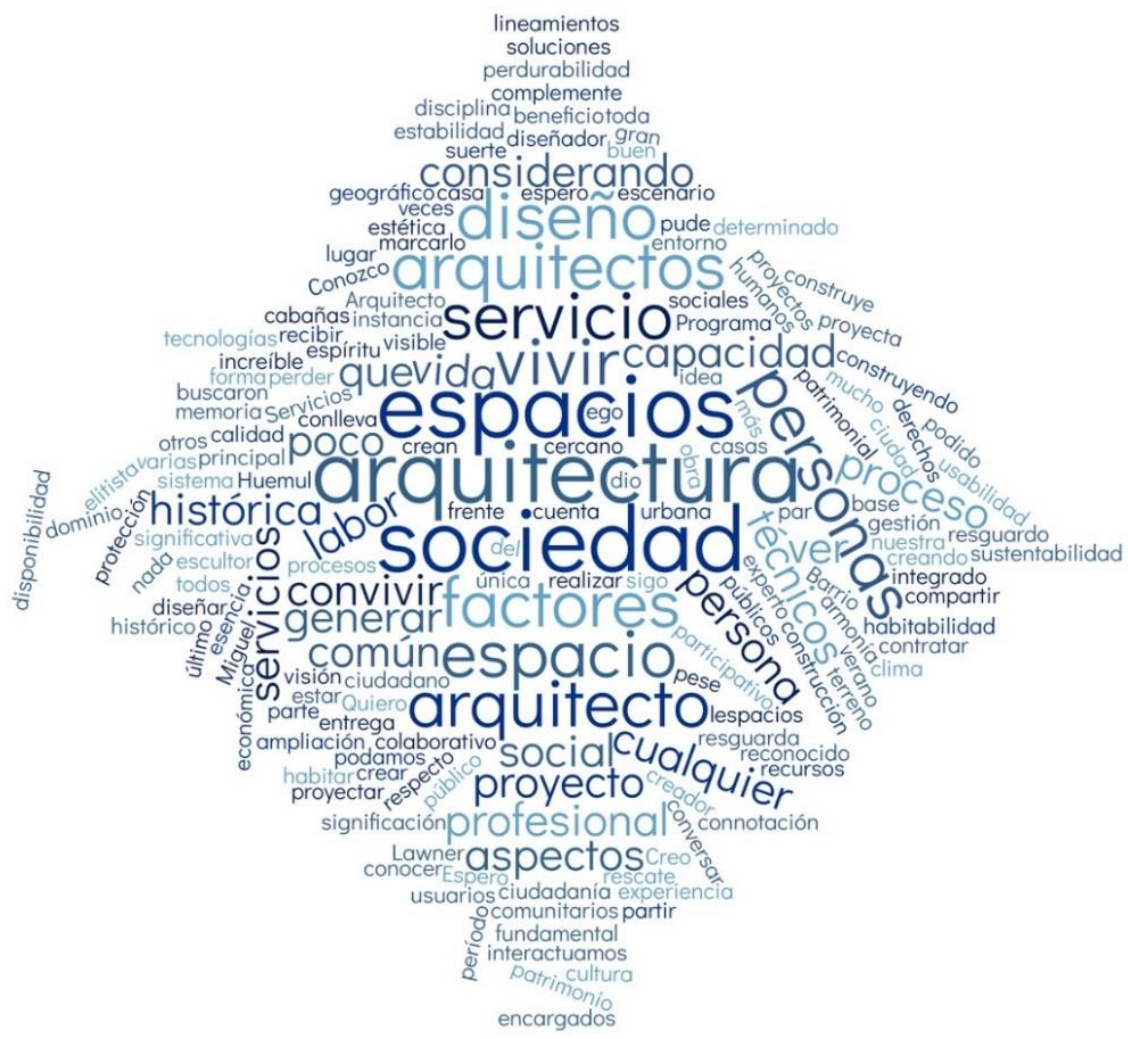

Fuente: Elaboración propia a través de nubedepalabras.es

ACE, 15 (4.5) CC BY-ND 3.0 ES | UPC Barcelona, España | Barrio Matadero-Franklin, de mercado popular a barrio

artístico-cultural. Conservación y capitalización, a través de turismo creativo y co-creación. DOI http://dx.doi.org/10.5821/ace.15.45.9528 
Figura 3. Nube de palabras correspondientes a la sesión de entrevistas a

"La voz del barrio Matadero Franklin" sobre la XXI Bienal en específico

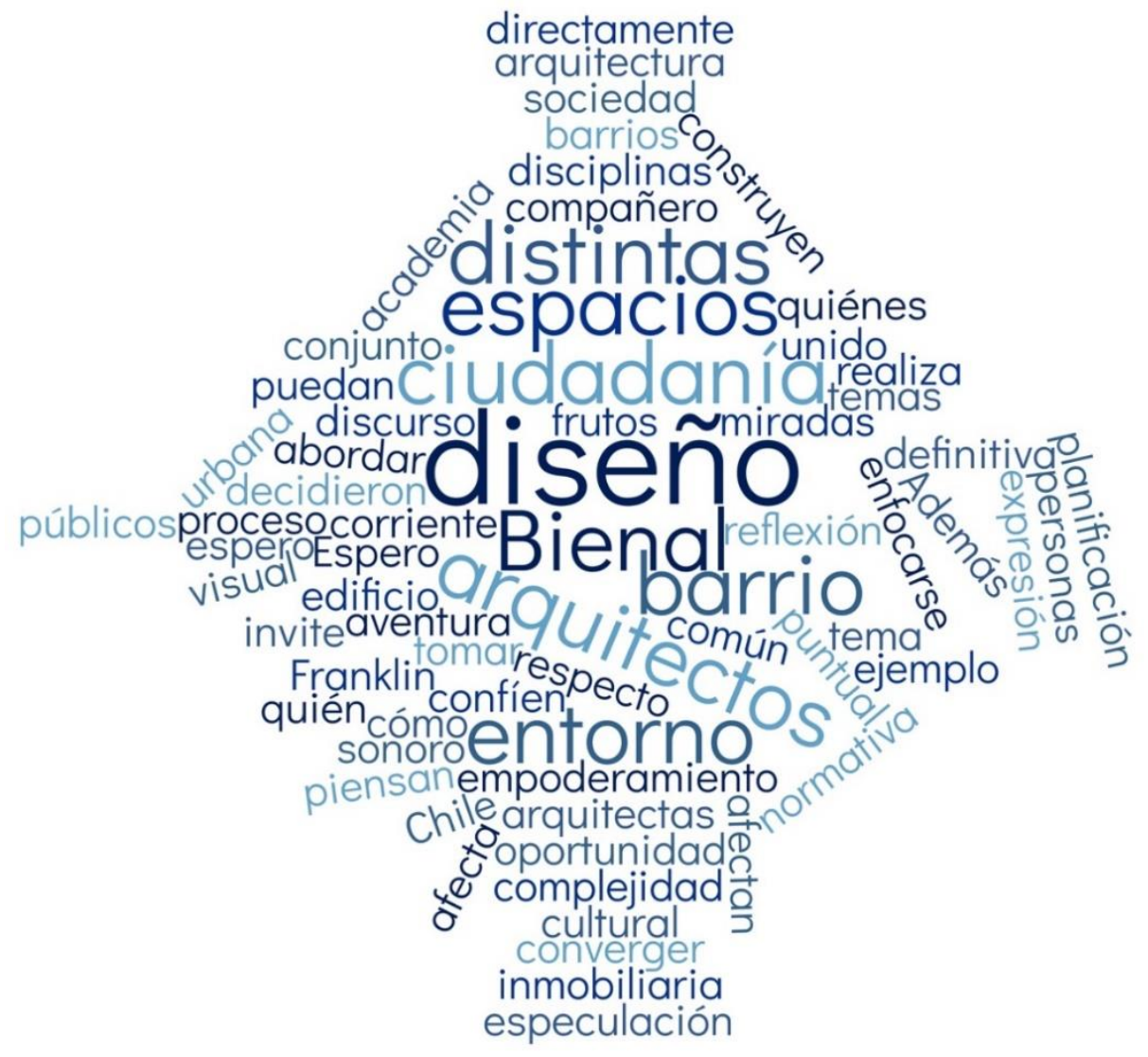

Fuente: Elaboración propia a través de nubedepalabras.es

La nube de (Figura 2) indica que conceptos como arquitecto, espacios, diseño, sociedad, personas, vivir, convivir y servicios son los más tratados al preguntar sobre la concepción que se tiene sobre la cotidianeidad de la arquitectura y la Bienal. Por otra parte, (Figura 3) muestra que la Bienal es asociada por los entrevistados a conceptos como arquitectos, diseño, entorno, espacios y ciudadanía, ya que son los más tratados al preguntar sobre la concepción que se tiene de lo común y lo corriente, una bienal y arquitectura.

\subsection{Creación de la identidad de barrio artístico-cultural a través del desarrollo de la Bienal de Arquitectura y Urbanismo}

El segundo objetivo es analizar los resultados de acciones realizadas para posicionar la marca "Barrio Matadero Franklin" como barrio artístico-cultural a través de la Bienal, realizado una revisión detallada de diversas web, redes sociales e información en prensa referenciada a Barrio Matadero Franklin y a la Bienal de Arquitectura y Urbanismo.

Los resultados obtenidos del análisis de diversas páginas web, redes sociales y blogs respecto a Barrio Matadero Franklin y la Bienal, permiten comprender que fortalecer la marca de la Bienal, resultó ser un facilitador para potenciar el Barrio Matadero Franklin. Se observa lo siguiente:

ACE, 15 (4.5) CC BY-ND 3.0 ES | UPC Barcelona, España | Barrio Matadero-Franklin, de mercado popular a barrio artístico-cultural. Conservación y capitalización, a través de turismo creativo y co-creación. DOI http://dx.doi.org/10.5821/ace.15.45.9528 
- Identificación de la zona o territorio o barrio: En el caso de Barrio Matadero Franklin la delimitación geográfica resulta clara.

- Valor de la personalización: Barrio Matadero Franklin es único, posee mercados de segunda mano, con productos únicos, además existe una variada oferta de café y restaurantes de comida local junto a diversas rutas tales como la ruta patrimonial, gastronómica, vintage, del vinilo, del juguete, cultural, del diseño y natural.

Tabla 1. Notas de prensa respecto a XXI Bienal de Arquitectura en Barrio Matadero-Franklin

\begin{tabular}{|c|c|}
\hline Titular & Fuente \\
\hline $\begin{array}{l}\text { La Bienal de Arquitectura se toma Franklin y el persa } \\
\text { con más de actividades gratuitas. }\end{array}$ & $\begin{array}{l}\text { Zambra, D. (2 de octubre de 2019). La Bienal de } \\
\text { Arquitectura se toma Franklin y el persa con más de } \\
250 \text { actividades gratuitas La Tercera. Recuperado de } \\
\text { https://finde.latercera.com/cultura-pop/bienal-de- } \\
\text { arquitectura-2019-franklin-persa/ }\end{array}$ \\
\hline $\begin{array}{l}\text { Cerca de } 250 \text { actividades trae la Bienal de } \\
\text { Arquitectura y Urbanismo } 2019 .\end{array}$ & $\begin{array}{l}\text { Cooperativa (2 de octubre de 2019). Cerca de } 250 \\
\text { actividades trae la Bienal de Arquitectura y Urbanismo } \\
2019 \quad \text { Cooperativa. Recuperado de } \\
\text { https://www.cooperativa.cl/noticias/cultura/arte/cerc } \\
\text { a-de-250-actividades-trae-la-bienal-de- } \\
\text { arquitectura-y-urbanismo-2019/2019-10- } \\
\text { 02/181113.html }\end{array}$ \\
\hline $\begin{array}{l}\text { Hoy comienza la Bienal de Arquitectura: Evento de } \\
\text { casi un mes que tendrá casi } 250 \text { actividades abiertas } \\
\text { al público. }\end{array}$ & $\begin{array}{l}\text { Gattás, C. (3 de octubre de 2019). Hoy comienza la } \\
\text { Bienal de Arquitectura: evento de casi un mes que } \\
\text { tendrá casi } 250 \text { actividades abiertas al público Radio } \\
\text { Rock \& \& Rep. Recuperado de } \\
\text { https://www.rockandpop.cl/2019/10/hoy-comienza- } \\
\text { la-bienal-de-arquitectura-evento-de-casi-un-mes- } \\
\text { que-tendra-casi-250-actividades-abiertas-al- } \\
\text { publico/ }\end{array}$ \\
\hline
\end{tabular}

Fuente: Elaboración propia.

- Utilidad de selección o elección por parte de los usuarios: Barrio Matadero Franklin ha transitado de ser considerado un mercado popular a un barrio que alberga cultura y actividades artísticas, lo cual lo consolida como un barrio artístico-cultural.

- Garantía: La marca Bienal de Arquitectura bajo el lema "Lo común y lo corriente" en Barrio Matadero Franklin, representa una expectativa de recursos a encontrar por parte de los posibles consumidores y visitantes. Barrio Matadero Franklin, no sólo es mercado popular, sino que posee diversas rutas culturales. Barrio Matadero Franklin posee asociaciones tales como el Grupo Asociativo Local Territorio Franklin que salvaguardan lo que sucede en el barrio y se ocupa del desarrollo local.

- Valor Lúdico: Se realizan periódicamente actividades culturales en la Galería La Curtiembre del Persa Víctor Manuel, con actividades dirigidas a toda la comunidad. Por otro lado, se abre espacio a actividades puntuales que capitalicen positivamente el lugar, tal como fue el caso de la puesta en escena de la Bienal.

El Barrio Matadero Franklin, invita a que se genere turismo creativo tanto en su espacio público como privado, las calles son espacios aprovechados para el pequeño comercio los fines de semana. En la misma línea la Bienal bajo el lema "Lo común y lo corriente" aprovechan justamente de proyectar las

ACE, 15 (45) CC BY-ND 3.0 ES | UPC Barcelona, España | Barrio Matadero-Franklin, de mercado popular a barrio 10 artístico-cultural. Conservación y capitalización, a través de turismo creativo y co-creación. DOI http://dx.doi.org/10.5821/ace.15.45.9528 


\section{ACE Architecture, City and Environment}

intervenciones en espacios públicos de fácil acceso para los residentes y visitantes. Y además se potencia la idea de co-crear experiencias entre locatarios, visitantes y residentes, haciéndolos parte de lo que estaba sucediendo para la Bienal. Se realizaron talleres, presentaciones de libros, foros, conversatorios, conferencias con el fin de tener presencia y participación de toda la ciudadanía, considerando a los vecinos del barrio, locatarios, visitantes, universidades, etc.

La Bienal realizó trabajo comunicacional para promocionar la marca, tanto in situ como en sus redes sociales oficiales. Además, se realizó un mapa oficial impreso para ser entregado a los visitantes durante los días de la Bienal, junto con un catálogo oficial de cuatro tomos para plasmar lo que fue la experiencia del evento.

En sus redes sociales se comunicaron las diversas actividades diarias en la cuenta oficial de la Bienal en Instagram (Figura 4).

Figura 4. Contenido comunicado en el Instagram oficial de la Bienal

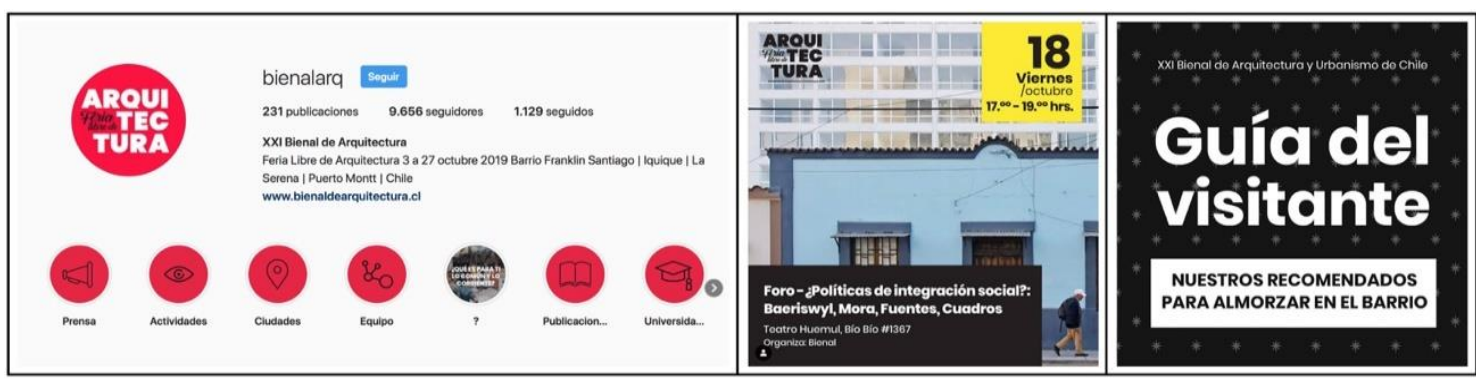

Fuente: Contenido comunicaciones de cuenta Instagram.

Del punto de vista in situ, se realizaron diversas acciones tales como la creación del logotipo oficial (Figura 5), informativos para la vía pública y un mapa con los principales puntos de interés a visitar. Pero también se realizó trabajo conjunto a las universidades, desarrollando carros de madera pertenecientes a las diversas universidades participantes (Figura 6).

Figura 5. Logotipo oficial Feria Libre de Arquitectura y logotipo Matadero-Franklin

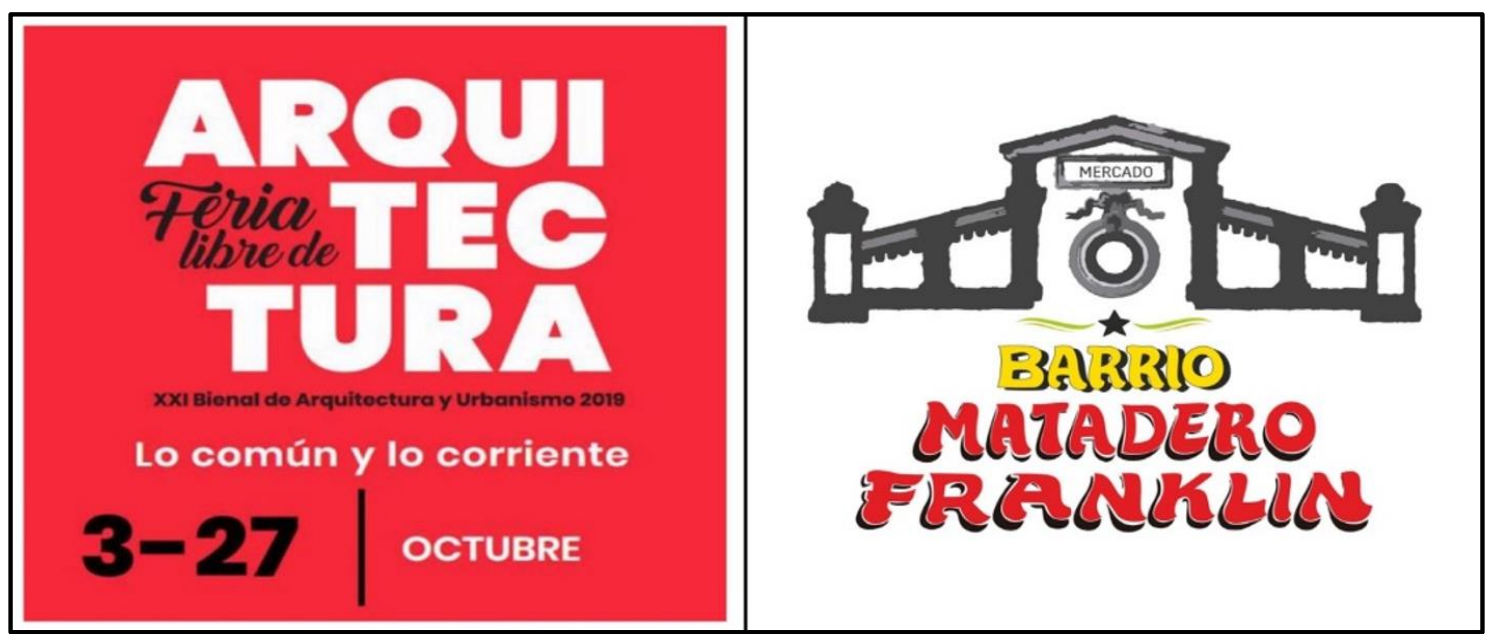

Fuente: Logotipos oficiales. Monroy, P. y Coeffé, B. (2019).

ACE, 15 (4.5) CC BY-ND 3.0 ES | UPC Barcelona, España | Barrio Matadero-Franklin, de mercado popular a barrio artístico-cultural. Conservación y capitalización, a través de turismo creativo y co-creación. DOI http://dx.doi.org/10.5821/ace.15.45.9528 


\section{ACE Architecture, City and Environment}

E-ISSN 1886-480

Figura 6. Activaciones de la Bienal en el Barrio Matadero Franklin

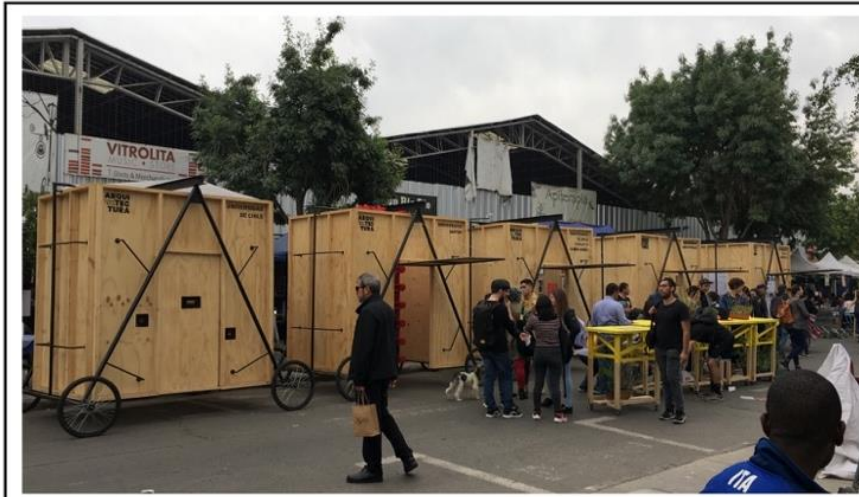

Carros de madera pertenecientes a las universidades participantes, dónde estudiantes exhiben sus obras a la comunidad.

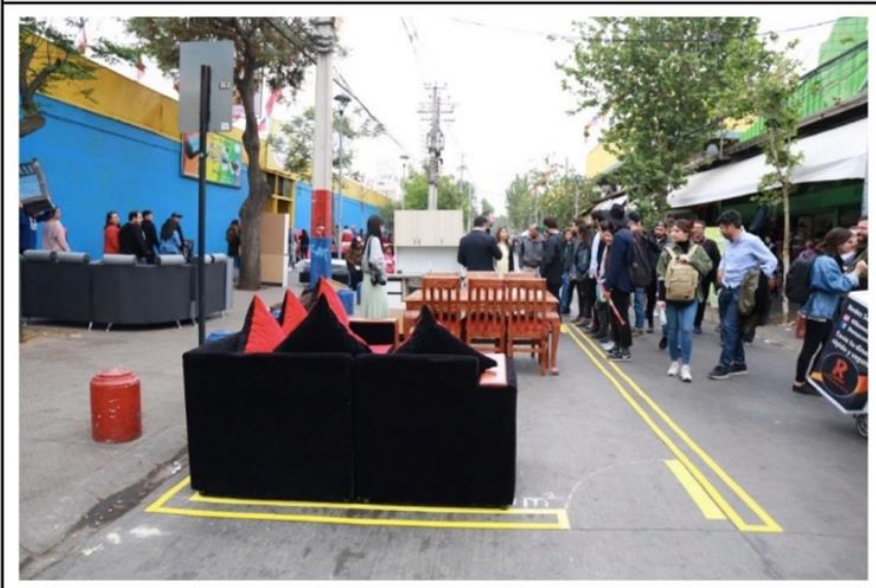

Intervención urbana "De lo doméstico a lo público" realizado por alumnos de la Universidad Técnica Federico Santa María.

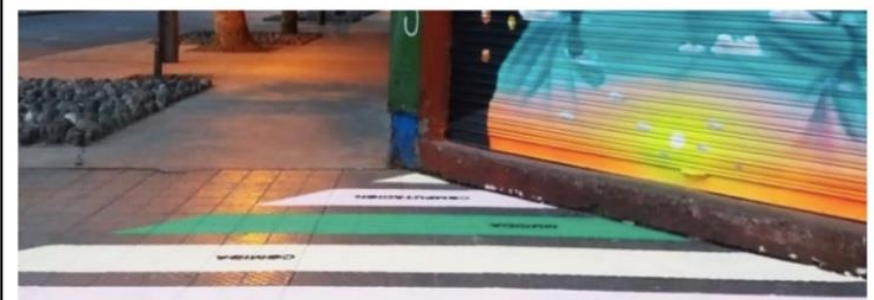

-enturnomen

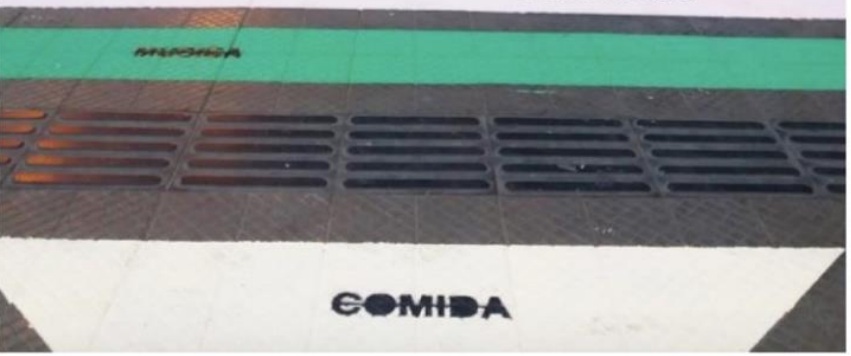

Intervención "Navegando el Persa" realizado por alumnos de la Universidad de Valparaíso y San Sebastián en las inmediaciones del Persa Victor Manuel.

Fuente: Fotografías del Barrio en días del evento. Monroy, P. (2019).

ACE, 15 (4.5) CC BY-ND 3.0 ES | UPC Barcelona, España | Barrio Matadero-Franklin, de mercado popular a barrio

artístico-cultural. Conservación y capitalización, a través de turismo creativo y co-creación. DOI: http://dx.doi.org/10.5821/ace.15.45.9528 
Con todo lo anterior, queda en manifiesto que acciones de turismo creativo y co-creación se hacen presentes con la bienal, logrando dar un vuelco a la imagen del barrio de ser tan sólo el barrio de los mercados hacia una concepción de un barrio con componentes artísticos y culturales.

El estudio identifica que la concepción que se tiene de la cotidianidad de la arquitectura y la Bienal está asociada al diseño, la sociedad, las personas y los espacios de convivencia. Además, se percibe una relación entre fortalecimiento de la marca Matadero Franklin y la Bienal, ya que se consigue una mayor identificación del barrio como un destino único, un barrio artístico-cultural y no únicamente mercado popular y, en definitiva, un destino que invita a las actividades creativas y experienciales.

\section{Conclusiones}

Los barrios indiferenciados y con un incipiente desarrollo turístico, han de revitalizar sus estrategias para atraer más visitantes y acercar a sus comunidades locales a ser parte de la oferta que ofrecen. De este modo, es que los barrios cobran valor y se diferencian entre sí, consolidándose dentro de la gama de alternativas para visitar o consumir existentes.

El presente trabajo estudia cómo, a través del desarrollo estratégico de turismo creativo y cocreación, se puede fortalecer la imagen de marca de un barrio con escaso desarrollo artístico-cultural.

Revisados diversos casos de éxito en otros proyectos de patrimonio industrial y conservación en diferentes países y contextos, tales como el caso de Tate Modern en Londres, Caixa Forum, Fundación Canal Isabel II y Tabacalera en Madrid y Centro Azuna en Bilbao, se concluye que desarrollar estrategias de turismo creativo y co-creación puede generar efectos positivos en el desarrollo socioeconómico de un barrio emplazado en un espacio geográfico delimitado.

Se selecciona el caso de la XXI Bienal de Arquitectura y Urbanismo, 2019 (Barrio Matadero-Franklin en Santiago de Chile), debido a que es el primer barrio en Chile en llevar a cabo una feria libre de arquitectura, con puestas en escena tanto en el espacio público como privado del barrio.

El presente estudio es significativo porque Barrio Matadero-Franklin es un barrio icónico de mercados populares en la capital chilena y, debido a ello, ha sido seleccionado para desarrollar la XXI Bienal de Arquitectura y Urbanismo 2019 y recibir a los artistas implicados y a los visitantes al evento. Se observa que el realizar estrategias concretas de puesta en valor del barrio, acercan a diversos grupos de interés que revitalizan y consolidan el barrio, lográndose así una transición de un barrio conocido por sus mercados populares hacia un barrio artístico y cultural que ofrece un valor agregado a la experiencia de quiénes lo visiten. Las estrategias desarrolladas son planteadas a largo plazo, lo cual se observa en las diversas acciones que se han realizado tanto físicamente en el barrio como en la comunicación de este a través de las redes sociales oficiales que gestiona la administración del barrio junto con lo que se informa en el sitio web oficial de Yo Amo Barrio Franklin (Figueroa y Guzmán, 2016).

Se concluye que estrategias de Marketing Urbano y Cultural, tales como el desarrollo de turismo creativo, junto con la co-creación de experiencias por parte del Barrio con el fin de posicionar la

ACE, 15 (4.5) CC BY-ND 3.0 ES | UPC Barcelona, España | Barrio Matadero-Franklin, de mercado popular a barrio 13 artístico-cultural. Conservación y capitalización, a través de turismo creativo y co-creación. DOI: http://dx.doi.org/10.5821/ace.15.45.9528 
marca "Barrio Matadero-Franklin" en los diferentes medios de comunicación, han sido estrategias que beneficiarán la imagen de marca del barrio. Dichas estrategias traerán efectos positivos en el desarrollo, tanto social como económico, en los diversos grupos de interés existentes, tanto en el corto como en el largo plazo.

\section{Autoría}

Stefania Pareti ha conceptualizado la investigación y analizado los datos secundarios, además de coescribir el trabajo. Blanca García-Henche ha conceptualizado y diseñado la investigación, realizado el estudio del marco teórico y coescrito el trabajo.

Conflicto de intereses: Los autores declaran que no hay conflicto de intereses.

\section{Bibliografía}

Adamo, G.E., Ferrari, S. y Gilli, M. (2019). Creativity as a source of differentiation in urban tourism: The case of Torino city. International Journal of Tourism Research, 21(3), 302-310. DOI: https://doi.org/10.1002/jtr.2261

Amin, A. y Robins, K. (1992). The re-emergence of regional economies? The mythical geography of flexible accumulation. Environment and Planning Society and Space, 8, 7-34. DOI: https://doi.org/10.1068/d080007

Bakas, F.,Duxbury, N.,Remoaldo, P. y Matos, O. (2019), The social utility of small-scale art festivals with creative tourism in Portugal. International Journal of Event and Festival Management, 10(3) 248-266. DOI: https://doi.org/10.1108/IJEFM-02-2019-0009

Bayliss, D. (2007). The rise of the creative city: culture and creativity in Copenhagen. European Planning Studies, 15(7), 889-903. DOI: https://doi.org/10.1080/09654310701356183

Brzozowska, B. (2016). Creative city as a brand-the caso of Łódź. Journal of Creative Studies, 9(1) 314. DOI: $10.3846 / 23450479.2015 .1112312$

Cooperativa (2 de octubre de 2019). Cerca de 250 actividades trae la Bienal de Arquitectura y Urbanismo 2019 Cooperativa. Recuperado de https://www.cooperativa.cl/noticias/cultura/arte/cercade-250-actividades-trae-la-bienal-de-arquitectura-y-urbanismo-2019/2019-10-02/181113.html

De Bruin, A. y Jelinčić, D. (2016), Toward extending creative tourism: participatory experience tourism. Tourism Review, 71(1), 57-66. DOI: https://doi.org/10.1108/TR-05-2015-0018

De Jorge-Huertas, V. (2020). Collaborative designing of communities: Helsinki and Zurich Pioneers. ACE: Architecture, City and Environment, 15(43), 9012. DOI: http://dx.doi.org/10.5821/ace.15.43.9012

Duque Franco, I. (2015). La cultura como estrategia de transformación y promoción urbana en Bogotá y Medellín. Revista Geografía Norte Grande, 25-43. DOI: http://dx.doi.org/10.4067/S0718$\underline{34022015000200003}$

ACE, 15 (4.5) CC BY-ND 3.0 ES | UPC Barcelona, España | Barrio Matadero-Franklin, de mercado popular a barrio artístico-cultural. Conservación y capitalización, a través de turismo creativo y co-creación. DOI. http://dx.doi.org/10.5821/ace.15.45.9528 
Felicetti, M. (2016). Cultural innovation and local development: Matera as a cultural district. ProcediaSocial and Behavioral Sciences, 223, 614-618. DOI: 10.1016/j.sbspro.2016.05.366

Florida, R. (2002). The economic geography of talent. Annals of the American Association of Geographers, 92, 743-755. DOI: https://doi.org/10.1111/1467-8306.00314

Gattás, C. (3 de octubre de 2019). Hoy comienza la Bienal de Arquitectura: evento de casi un mes que tendrá casi 250 actividades abiertas al público Radio Rock \& Pop. Recuperado de https://www.rockandpop.cl/2019/10/hoy-comienza-la-bienal-de-arquitectura-evento-de-casi-unmes-que-tendra-casi-250-actividades-abiertas-al-publico/

Figueroa, M y Guzmán, T. (2016). Guía Barrio Franklin, Un mercado popular para Santiago. Yo Amo Barrio Franklin. Santiago, Chile: Consejo Nacional de las Culturas y las Artes.

Herrán Gascón, A.; Cortina Selva, M. y González Sánchez, I. (2006). La muerte y su didáctica. Manual para educación infantil, primaria y secundaria. Madrid, España: Universitas.

Hudson, C., Sandberg, L. y Schmauch, L. (2017). Th eco-creation of culture? The case of Umeå, European Capital of Culture 2014. European Planning Studies, 25(9), 1538-1555. DOI: https://doi.org/10.1080/09654313.2017.1327032

Juarranz, A. (2017). Mundane beauty in art and architecture. Ge-Conservación, 11, 196-201. DOI: https://doi.org/10.37558/gec.v11i0.476

Kirchberg, V. y Kagan, S. (2013). The roles of artists in the emergence of creative sustainable cities: Theoretical clues and empirical illustrations. City, Culture and Society, 4(3), 137-152. DOI: $10.1016 /$ j.ccs.2013.04.001

Liu, Y-D. (2014). Cultural events and cultural tourism development: Lessons from the European capitals of culture. Journal of European Planning Studies, 22(3), 498-514. DOI: https://doi.org/10.1080/09654313.2012.752442

Marques, L. y Borba, C. (2017). Co-Creating the city: Digital technology and creative tourism. Tourism Management Perspectives, 24, 86-93. DOI: 10.1016/j.tmp.2017.07.007

Mc Guigan, J. (2016). Creative Class, Neoliberal Culture, 139-149, Palgrave Macmillan, London. Monroy.

Moreno, M.B, (2019). Barrio Franklin En Terreno. Recuperado de: https://www.enterreno.com/blogs/barrio-franklin

Monroy, P. y Coeffé, B. (2019). XXI Bienal de Arquitectura y Urbanismo de Chile. Lo común y lo corriente.

Monroy, P. (2019). Bienal de Arquitectura. Recuperado de: https://www.bienalarquitectura.cl/

Mumford, L. (2016). La cultura de las ciudades. Open Road Media.

Napadensky, A. (2020). ¿Un viejo centro, para nuevos usos? Distribución espacial de Servicios Intensivos en Conocimiento [SIC] en el Área Metropolitana de Concepción [AMC], Chile. ACE: Architecture, City and Environment, 15(44), 9210. DOI: http://dx.doi.org/10.5821/ace.15.44.9210

Peck, J. (2005). Struggling with the creative class. International Journal of Urban and Regional Research, 29(4), 740-770. DOI: https://doi.org/10.1111/j.1468-2427.2005.00620.x

ACE, 15 (4.5) CC BY-ND 3.0 ES | UPC Barcelona, España | Barrio Matadero-Franklin, de mercado popular a barrio 15 artístico-cultural. Conservación y capitalización, a través de turismo creativo y co-creación. DOI http://dx.doi.org/10.5821/ace.15.45.9528 
Rabazauskaité, V. (2015). Revitalization of public spaces in the context of creative tourism. Journal of Creative Studies, 8(2), 124-133. DOI: https://doi.org/10.3846/23450479.2015.1053543

Radaelli-Muuronen, B. (2019). The role of Helsinki contemporary art biennial in placemaking and city branding: An interdisciplinary study on the establishment of a new cultural event. Helsingfors universitet, Matematisk-naturvetenskapliga fakulteten.

Richards, G. (2019). Creative Tourism: opportunities for smaller places? Tourism \& Management Studies, 15, 7-10. DOI: 10.18089/tms.2019.15SI01

Richards, G. (2014). Creativity and tourism in the city. Current Issues in Tourism, 17(2) 119-144. DOI: https://doi.org/10.1080/13683500.2013.783794

Richards, G. (2011). Creativity and tourism: The state of the art. Annals of Tourism Research, 38(4), 1225-1253. DOI: https://doi.org/10.1016/j.annals.2011.07.008

Richards, G. (2000). Tourism and the world of culture and heritage. Tourism Recreation Research, 25(1), 9-17. DOI: https://doi.org/10.1080/02508281.2000.11014896

Richards, G., \& Wilson, J. (2006). The creative turn in regeneration: creative spaces, spectacles, and tourism in cities. En M. Smith (Ed.), Tourism, culture, and regeneration (pp. 12-24). CABI. https://doi.org/10.1079/9781845931308.0012

Rosenstein, C. (2011). Cultural development and city neighborhoods. City, Culture and Society, 2(1) 915. DOI: $10.1016 /$ j.ccs.2011.02.002

Scott, A. (2006). Creative Cities: Conceptual issues and policy questions. Journal of Urban Affairs, 28(1) 1-17. DOI: https://doi.org/10.1111/j.0735-2166.2006.00256.x

Sepe, M. y Di Trapani, G. (2010), Cultural tourism and creative regeneration: two case studies. International Journal of Culture, Tourism and Hospitality Research, 4(3) 214-227. DOI: https://doi.org/10.1108/17506181011067600

Vanolo, A. (2008). The image of the creative city: Some reflections on urban branding in Turin. Cities, 25(6), 370-382. DOI: https://doi.org/10.1016/j.cities.2008.08.001

Zambra, D. (2 de octubre de 2019). La Bienal de Arquitectura se toma Franklin y el persa con más de 250 actividades gratuitas La Tercera. Recuperado de https://finde.latercera.com/cultura-pop/bienalde-arquitectura-2019-franklin-persa/

Zukin, S. y Braslow, L. (2011). The life cycle of New York's creative districts: Reflections on the unanticipated consequences of unplanned cultural zones. City, Culture \& Society, 2(3), 131-140. DOI: https://doi.org/10.1016/j.ccs.2011.06.003

ACE, 15 (4.5) CC BY-ND 3.0 ES | UPC Barcelona, España | Barrio Matadero-Franklin, de mercado popular a barrio artístico-cultural. Conservación y capitalización, a través de turismo creativo y co-creación. DOI http://dx.doi.org/10.5821/ace.15.45.9528 